Representing Tibet in Chinese Independent Documentaries:

New Aesthetic of Space and Time

\author{
Yanqin Tan \\ Guangzhou, Guangdong, China
}

BA in Chinese Literature, Peking University (China), 2014

\begin{abstract}
A Thesis presented to the Graduate Faculty of the University of Virginia in Candidacy for the Degree of Master of Arts
\end{abstract}

\author{
East Asian Center
}

University of Virginia

May 2016 
Tibet is one of the most appealing areas in the world due to its geographical and religious uniqueness, which has invited numerous visual works from photographers and documentary filmmakers from around the world in recent years. Since the 1990s, Tibet is also of great significance in contemporary Chinese documentary filmmaking, among which some independent documentary $^{1}$ works such as No.16 South Barkhor Street (1997, by Duan Jinchuan), Gongbo's Happy Life (1999 by Ji Dan) has been domestically and internationally recognized. The former was the first Chinese film to win the Grand Prix at the Paris Cinema du Reel Documentary Film Festival, while the later was invited to Taiwan International Documentary Biennale in 2000 and to Yunnan Multi Culture Visual Festival (Yunfest) in 2001.

No.16 Barkhor Street has received great attention from the academia in China and in the West, and is celebrated as almost a model of direct cinema. Chris Berry admires Duan Jinchuan's work for its conscious distance from the pedagogical project and its preference for pure observation, which he regards as one of the main features of being "independent" in contemporary Chinese documentary filmmaking. ${ }^{2}$ Admittedly, No.16 Barkhor Street plays an important role in contemporary Chinese documentary and marks a pivotal transition. However, what intrigues me most is not only its weight in the development of documentary as a genre, but also what and how it presents us about its subject: Tibet. As I will argue later, benefitting from an

\footnotetext{
${ }^{1}$ Independent documentary is a category more established in the North American academia. A Chinese scholar, Xinyu Lü, names them as "New Documentary," which is also adapted by the Europe-based scholar Chris Berry. See Chris Berry, Lü Xinyu, and Lisa Rofel, The New Chinese Documentary Film Movement: for the Public Record. Hong Kong: Hong Kong University Press, 2010.

${ }^{2}$ Chris Berry, "Independently Chinese: Duan Jinchuan, Jiang Yue, and Chinese Documentary.” In Paul G. Pickowicz and Yingjin Zhang. From Underground to Independent: Alternative Film Culture in Contemporary China. Lanham: Rowman \& Littlefield Publishing Group, 2006. pp. 109-122.
} 
aesthetics of spontaneity, immediacy and on-the-spot realism, this film changes the temporality and spatiality in the cinematic representation of Tibet, and thus change the politics of looking and being seen between the Han audience and the Tibetan subjects. The same trend can be also found in Gongbo's Happy Life. My goal in this paper is to examine what I call the new Tibetan documentary in the 1990s and to explore its politics of time and space in representing Tibet. By putting them into a broader context of Tibet-related films in China since the 1950s, I aspire to grapple with not only the aesthetic of the new documentary, but also its historical significance in Tibetan cinema.

1. Backgrounding New Tibetan Documentary: A History

Cinematic attention to Tibet does not occur only since the 1990s, the first phase of prosperity of Tibetan documentaries was the 1950s, when socialist realist documentaries were highly promoted by the state. Films on Tibet at that time were mostly produced by state-run film studio and thus shadowed by state ideology. The documentary Zhongguo minzu da tuanjie (Great Unity of Chinese Nation, 1950) captures the grand scene of ethnic-minority representatives, including Tibetan living Buddha and Lama, going to Beijing for a celebration of the first National Day of PRC. Since then, more and more newsreels (xinwen jilupian) were filmed particularly on Tibet, such as Jiefang Xizang da xingjun (Marching to Liberate Tibet, 1950), Guangming zhaoyao zhe Xizang (The Sun Shine on Tibet, 1951), Xizang zhijing tuan (A Salute Group from Tibet, 1953), Cong Xizang dao Beijing (From Tibet to Beijing, 1955), Chun dao 
Xizang (Spring Going to Tibet, 1956), Pingxi Xizang panluan (Pacifying the Tibetan Repression,

1959), Ganzi zangzu renmin de chuntian (The Spring of Garza Tibetans, 1959), Ganzi zangzu

renmin de kongsu (An Accusation From Garza Tibetans, 1959), Baiwan nongnu zhanqilai (A

Million Slaves Stand Up, 1959). ${ }^{3}$ Two documentaries on the construction of the Sichuan-Tibetan

highway and Qinghai-Tibetan highway, Zhansheng Nujiang tianxian (Overcoming the Barrier of

Nu River, 1954) and Tongxiang Lasa de xingfu daolu (Happy Highway to Lhasa, 1956) were

done, too. Class struggle, liberation and modernization are three major themes in the first

hey-day of Tibetan documentary.

The 1990s witnesses a boom of independent documentaries on the same region. Besides the two award-winning works mentioned above, Duan Jinchuan's cohorts, Jiang Yue and Wen Pulin, have also contributed a number of works to this growing field, including Tibetan Lama Circus (Lama Zangxi Tuan, 1991, by Jiang), Catholicism in Tibet (Tianzhu zai Xizang, 1992, by Jiang), The Sacred Site For Asceticism (Qingpu: kuxiuzhe de shengdi, 1992, by Duan and Wen), Gema Baqin (1995, by Wen), Tibet 10 Years (Zai zang shinian, 1997, by Wen), Nuns on the Minqiong Mountain (Minqiong shan ani, 199?, by Wen) and Celestial Burial (Tian zang, 2003, by Wen). These documentaries present a rich picture of Tibet by opening up new space for its unique religious experience and daily life, which were absent in the previous socialist realist documentaries and other forms of cinematic representation. These Tibet-related documentary

\footnotetext{
${ }^{3}$ A Chinese Ph.D dissertation (unpublished) in Fudan University (China) has done a brilliant job in creating a filmography of Chinese documentaries on ethnic minorities produced in 1949 to 1978. See Wang Hua, Minzu yingxiang yu xiandaihua jiamianli: Xinzhongguo shaoshu minzu ticai jilupian lishi yu jiangou (1949-1978) (Ethnic Cinema and the Coronation of Modernization: The History and Construction of Documentaries on Ethnic Minorities in New China). I learned this dissertation and some of its content from Lü Xinyu, "Xinzhongguo shaoshu minzu yingxiang shuxie: Lishi yu zhengzhi” (New Chinese Ethnic Minorities Cinema and Writing: History and Politics), Shanghai: Journal of Shanghai University (Social Science), Vol. 32, No. 5.
} 
films in the 1990s constitute what I call "new Tibetan documentary."

By calling it "new Tibetan documentary," I am proposing a conversation to what Lü Xinyu, a Chinese scholar, calls the "New Documentary Movement" in China. The Tibetan documentaries in the 1990s share certain features with the non-Tibet-related new documentaries produced at the same period in terms of their preference for direct cinema, on-the-spot realism and the use of long takes. All of these new filming techniques speak of a break up with the socialist realist documentaries in a former era. As Yingchi Chu observes, all socialist realist documentary filmmaking in the 1950s were highly influenced by Lenin's definition of documentary as "visual illustration of political ideology." It is the new documentary in the late 1980s and early 1990s that invoked the ontological and epistemological function of documentary as a genre.

Before delving specifically into the spatiality and temporality of these films and the distinction between the socialist realist documentaries and the new documentaries in filming Tibet, I feel necessary to give enough credit to the production mode of independent filmmaking in the 1990s, which is an essential social context for all the vigor of the new Tibetan documentary. Arguably, new Tibetan documentaries are an integral part of China's "New Documentary Movement." The involvement of independent documentaries in filming Tibet is, as I will contend, conscious as well as accidental.

According to Lü Xinyu, the "New Documentary Movement" began in the late 1980s and

\footnotetext{
${ }^{4}$ See footnote 1.

5 Yingchi Chu, Chinese Documentaries: From Dogma to Polyphony. London: Routledge, 2007, pp. 14 \& 45.
} 
prospered since the 1990s, and thus must be read within the social context of that period. ${ }^{6}$ The 1980s is a controversial period in China. On the one hand, after the nation-wide turbulence during the Cultural Revolution, the nation decided to open up to the outside world and to take in new ideas of liberty and democracy from the outside in an active way; on the other hand, the intellectual desire for liberty and democracy largely exceeded the national agenda for political reforms. An unbridgeable gap between national will and individual idealism in the late 1980s deeply frustrated most of the Chinese intellectuals. The first Chinese independent documentary film, Bumming in Beijing: The Last Dreamers (1990, by Wu Wenguang), was exactly produced before, during and after the Tiananmen Accident. As Lü Xinyu remarks when conceptualizing the "New Documentary Movement," independent documentary filmmaking in China is constructed on "the ruin of a utopia." With the vanishing of a utopian impulse, a bunch of Chinese intellectuals (including filmmakers) retreated from political engagement and began to approach social reality from the bottom up. As Lü Xinyu vividly describes, The Tiananmen Incident shocked them. ... They discovered that they understood little about what China actually was. They felt the need to begin a new understanding of Chinese society. During the 1980s, they had examined China from on high. Now they felt the need to go to the grassroots, and to understand China's changes and their causes from this other vantage point. ${ }^{8}$

The huge impact of Tiananmen events "dismissed" the intellectual from Beijing to various

\footnotetext{
${ }^{6}$ Lü Xinyu, Jilu Zhongguo: Dangdai Zhongguo xinjilu yundong (Recording China: Contemporary Chinese New Documentary Movement). Beijing: Sanlian shudian, 2003. Also see Lü Xinyu, "Rethinking China's New Documentary Movement: Engagement with the Social," translated by Tan Jia and Lisa Rofel, in The New Chinese Documentary Film Movement, pp. 15-48.

${ }^{7}$ Lü Xinyu, Jilu zhongguo, p.1.

${ }^{8}$ Lü Xinyu, "Rethinking China's New Documentary Movement: Engagement with the Social." In Chris Berry, The New Documentary Film Movement. p.19.
} 
off-center spots, including suburban/countryside and the national frontiers. Tibet was one of their ideal choices due to its geographic remoteness and ethnic difference. At the beginning of his autobiographic documentary, Tibet 10 Years, Wen Pulin situated his career of Tibetan documentary filmmaking after the political oppression in the late 1980s. He is a Manchurian-born in northeast and was an art history student in Beijing. Once being passionate with experimental art to break up with all cultural heritages from the socialist era, he was so frustrated after the Tiananmen Incident that he "ran away" to Tibet. Although Tibet is not a conscious choice for Wen Pulin, the cultural difference of it did lead him to see the unfamiliar and unseen within China. Therefore, he took up his own camera to record a new Tibet beyond his previous imagination.

However, despite the sequential relationship between the Tiananmen Incident and the spread of filmmakers over the marginalized space of China, Yingjin Zhang situates the springing up of independent documentaries more broadly in a shared pursuit of "being independent of official ideology" and an "oppositional stance vis-à-vis the mainstream"10 among documentary filmmakers and the Six Generation filmmakers in the 1990s. Further than realizing their limit in understanding the social reality of China, the Chinese independents became aware of the limit of the propagandist tradition in discovering and presenting the truth and reality of China. In an earlier chapter addressing the "minority films," Yingjin Zhang has conceptualized the propagandist narrative driven by the overriding project of nation building from the 1950s to the

\footnotetext{
9 Yingjin Zhang, Cinema, Space, and Polylocality in a Globalizing China. Honolulu: University of Hawaii Press, 2010, pp. 106-107.

10 Ibid., 121.
} 
1970s as "state discourse," 11 which was questioned by the individual or minority discourse. As in the filmmaker, Duan Jinchuan's own words, "in the past, we have only one voice, or one system, one thinking in one ideological framework."12 In opposition to state discourse, the independents seek to renounce national identity and cultural myths, as well as to reclaim agency and space for subjectivity in the 90s. In contrast to Lü and other scholars, Zhang emphasizes that what the independent cinema directs is not the social reality in nature but "what they perceive ... as truth and reality."13 Ying Qian even claims it as a "power" in reconfiguring a public sphere. ${ }^{14}$ Zhang's articulation of the subjectivity in independent cinema (including independent documentary) is illustrative to my study on the space and time in new Tibetan documentary at a point that the new ones do not necessarily negate the previous works in documenting Tibet.

Rather, it provides new perspectives and new ways - an unfamiliar perspective of individual and ordinary - in looking into Tibet.

\section{From Place to Space}

In his groundbreaking work of the politics of everyday life and spatial practice, The

Practice of Everyday Life (1984), Michel de Certeau has marked the significant distinction between a place and a space.

A place (lieu) is the order (of whatever kind) in accord with which elements are

\footnotetext{
${ }^{11}$ Yingjin Zhang, Screening China: Critical Intervention, Cinematic Reconfigurations, and the Transnational Imaginary in Contemporary Chinese Cinema. Ann Arbor: The University of Michigan, 2002. pp. 151-206.

${ }_{12}$ An interview with Duan Jinchuan, in Wang Weici, Jilu yu tansuo: Yu dalu jilupian gongzuozhe de shiji duihua (Record and Explore: A Century Dialogue with the Documentary Filmmakers in Mainland), Taibei: Yuanliu chuban gongsi, 2000, p.148. The interview is conducted and recorded in Chinese, my own translation.

13 Yingjin Zhang, Cinema, Space, and Polylocality in a Globalizing China, p. 107.

14 Ying Qian, "Power in the Frame: China's Independent Documentary Movement." Chinese Media (2013).
} 
distributed in relationships of coexistence. ... A place is ... an instantaneous configuration of positions. It implies an indication of stability.

A space ... is composed of intersections of mobile elements. ... Space occurs as the effect produced by the operations that orient it, situate it, temporalize it, and make it function in a polyvalent unity of conflictual programs or contractual proximities.

In short, space is a practiced place. ${ }^{15}$

In my understanding, the distinction between a place and a space has two levels: totality and fragment, stability and mobility. However, the space is not outside of the place. Instead, it emerges within the place when concrete human actions and feelings are presented. In other words, space is defined by the intimacy between a person and where he is standing. In light of de Certeau's analysis, I will argue a change of Tibet from a place in the previous documentaries to a space in the independent documentaries.

In the socialist realist documentaries produced in the $50 \mathrm{~s}$, Tibet is a totalized place. In works such as A Million Slaves Stand Up and Happy Way to Lhasa, it was perceived as an area where people were suffering under class exploitation, and where later on experienced heartening modernization such as highway construction. The pictures and shots with sorrowful faces or delightful dances were selected to visualize the voiceover narration of class repression or modernization. Selected pictures and shots taken off from it original space and context represents Tibet as a whole. For the audience, Tibet in the documentary is just somewhere in China the

15 Michel de Certeau, The Practice of Everyday Life. Berkeley: University of California Press, 1988, p. 117. 
unfortunate and the fortunate were happening. In other words, Tibet in these films was nowhere; Nothing more than an "empty signifier," to borrow Saussure's term, to the real Tibet

The new Tibetan documentary shows a trajectory of opening up spaces for representing the different aspects of Tibetan life. For example, Wen Pulin's works on Tibetan living Buddha and monks, and nuns open up a religious space where practitioners chant and pray; Duan Jinchuan's work No.16 South Barkhor Street presents a public space at the center of Lhasa where local neighborhoods interact frequently with the staffs in the local government; Ji Dan's work Gongbo's Happy Life goes into the domestic space of an ordinary family where she sees the triviality and happiness of a common household.

No.16 South Barkhor Street and Gongbo's Happy Life are two ideal choices to detail the representation of a Tibetan space. No.16 South Barkhor Street locates its camera in No.16 South Barkhor Street, the local government building for the neighborhood committee and police station. This plotless film captures some major scenes, such as administrative meetings before the Tibetan New Year and religious day; an attempt of mediation into family quarrels and inter-ethnic disputes; a police interrogation of a thief; and some other trivial administrative stuff (e.g. accounting and registration). Duan Jinchuan's film is inspired and highly influenced by the American documentary filmmaker Frederick Wiseman and his non-interventionist work Central Park (1989), which also captures the flows of natural time in a public space. Prior to No.16 South Barkhor Street, Duan has earned his reputation in filming The Square (1994, co-produced with Zhang Yuan). In The Square, the two directors decipher the myths of Tiananmen Square as a 
political symbol of the nation through a sequence of everyday practices: intimate lovers wandering around, visitors taking pictures everywhere, local residents doing entertainment or exercise, soldiers chatting and walking in and out. The desymbolized square becomes a real space where people exist and live.

No.16 South Barkhor Street begins with a stare at the doorplate of the building. It is followed up by some engine noise and some vague radio sounds from the street before the camera turns to glance around the inner side of the building. It is an imitation of a person walking towards and then into the building, with certain unwanted noise. As the next shot shows a meeting of the neighborhood committee with local residents, clergies and security guards, the first shot is a gaze of an anonymous participant in the meeting. The camera continues to peer around at other participants' face while sometimes focusing on the speaker like an absent-minded person. The humanized camera opens up a concrete space in central Lhasa, and its intimacy with its surroundings exactly echoes what de Certeau calls "spatial practice" or "a spatial acting-out of the place."

In the socialist realist documentaries, a Tibetan person is merely a small part of a bigger picture under a celestial eye. Although some occasional close-ups can even capture a wrinkle on a person's forehead, but it is no more than an image alienated from its setting. The gap between the figure and the space he locates could only be filled up by voiceover narration of class struggle or modernization, as well as the audiences' imagination based on their own experience

\footnotetext{
${ }^{16}$ Ibid., p. 97.
} 
in the central regions of China. On the contrary, Duan Jinchuan and Ji Dan's films foreground human bodies navigating, mapping, and more importantly, appropriating the Tibetan spaces. Taking the government building as a central point, the camera also travels to other spots in downtown Lhasa following the police or committee staff. For instance, after the administrative meeting inside the building, the camera turns to the street on a religious day. In a long take moving into the street, a diversity of religious as well as secular activities, such as cleansing streets, running market stall, playing dharma-cakra and praying, are accommodated. Some of the scenes, especially the secular commercial activities and unpleasant criminal activities, are rather striking due to its absence in previous Tibetan cinema. If in de Certeau's study of city, space is forgotten as a consequence of the perception of the city as a "functionalist organization," in the Tibetan cinema case, some secular and quotidian practices and their space are forgotten as a result of a simplified and stereotyped conception of Tibet as a pre-modernized region with religious hue. Benefitting from a specific perspective from an ordinary local person, the reemergence of the elements that the state discourse neglects or excludes are allowed.

It is also worthy mentioning the random glance from the street up to a decoration on top of a temple. The golden animal-shape decoration is undoubtedly a religious symbol. However, in this particular space appropriated by a certain eye, it becomes a small part of local view, which happens to be about religion. All of these seemingly scattered and heterogeneous scenes, significant or insignificant, are tied to the administrative mission of the local government. The

\footnotetext{
${ }^{17}$ Ibid., p. 95.
} 
street as another enriched public space is appropriated by an anonymous eye - it is more likely

the gaze of a local official here. The camera intentionally follows and successfully represents the process of appropriation of the public space. As Frederick Wiseman comments on direct cinema, despite of its lack of a narrative structure, it is actually "creating a fiction based on nonfiction material that these things are related to each other in your mind. And the success of the film depends on the extent to which the whole film creates the illusion that these events have in fact some connection with each other."18 In Duan Jinchuan's film, the street elements are connected by the local issues and concerns that he has found out based on his own observation into local life, ${ }^{19}$ rather than by an presumed and imposed grand narrations such as modernization. Therefore, it is possible to suggest that, in this film, the Tibetan elements gain a renewal in a real space in terms of their intrinsic relationship. To put it another way, this film on the one hand fragments a homogenized Tibet, on the other hand reconstructs it.

If in No.16 South Barkhor Street signals an emergence of public space in Tibetan documentary, Gongbo's Happy Life presents us a Tibetan domestic space in an ordinary household. ${ }^{20}$ As indicated in the title, the film traces the quotidian life of Gongbo, a Tibetan man in Lhatse, another Tibetan city, at his middle age. This films portray Gongbo's life of upsets as well as happiness: Gongbo is upset with having too many (six) girls before he can have a second

\footnotetext{
${ }^{18}$ Ira Halberstadt, “An Interview with Frederick Wiseman." In Nonfiction Film: Theory and Criticism, ed. Richard Barsam, New York: E.P. Dutton \& Co., 1976. The interview first appeared in Filmmaker's Newsletter 7, no. 4 (1974): 25.

19 Before filming No.16 South Barkhor Street in 1995, Duan Jinchuan has been in Tibet for more than 10 years since 1984, working as a director and editor in a local television station.

20 Although they are different from each other in various ways, (for example, Gongbo 's Happy Life has a protagonist and a narrative structure; and Ji expresses more subjective opinion on her subject matters in films), these two films are of equal significance in my articulation of space and time in Tibetan documentary.
} 
son; with the outstanding loan for his tractor; with his eldest son who does not manage to earn a good living in the city. However, his life is not overwhelmed by the trivial troubles; the second boy finally comes and Gongbo continues to have a happy time working with friends and being with the family.

The film opens up two spaces in a Tibetan countryside - the domestic space of a nomadic family in an adobe house, and an open-air space on the mountain. All shots are made in these two scenes. My analysis of the space in Gongbu's Happy Life is, again, aligns with with de Certeau's theorization of spatial practice and the appropriation of space. As de Certeau articulates, walking around the city is the most common spatial practices - "to walk is to lack a place." 21 The appropriation of a place and the experiencing of a space exist in people's everyday life. Different from Duan Jinchuan's camera, which pretends to be an ordinary eye among those of the local residents to experience the space, Ji Dan distances herself from the family by positioning herself as a friend of the family rather than mimicking the perspective of a family member. Therefore, what I consider important in Ji Dan's case is her ability to capture the intimate relation between the subjects and the physical space they are located in - a Tibetan rural space for an ordinary Tibetan.

As a thinly populated region on the top of Tibetan Plateau, Tibet has the best view of clean water, blue sky and lush grass. Its beauty is frequently presented to audience nation-wide and world-wide. In the socialist realist documentaries or other TV documentary from the 1980s, the

\footnotetext{
${ }^{21}$ Michel de Certeau, p. 103.
} 
outstanding natural beauty of Tibet is never neglected. However, in most case, the beauty is no more than a gift to the outsiders, as if it is a jade of the locals that can be given away. In Ji Dan's work, in contrast, the relation between the natural beauty and the habitants is adjusted. Local natural beauty becomes the beauty to the locals. Similar to the pedestrian in de Certeau's city, people in a grand picture of Tibet begin to walk and to see in Gongbo's Happy Life. In one long take, Ji Dan accompanies Gongbo's five girls to the mountain where they help with mushrooming and herding sheep. The five girls gossip and giggle until they see the "Thor" (a lightening) on the sky. The camera captures their footsteps climbing up to the top of the rocks and then, their view up to the sky when one is pointing to it. All beautiful natural sceneries expected are excluded from Ji Dan's camera until her subjects spot it and appropriate it. In other words, what the documentary presents is not the local natural beauty for the audience, but an intimate relation between the view and the locals. Another revealing shot is filmed after a rain shower. The sudden shower stops the family from working outside and forces them back under the roof. After the shower, the rainbow appears in the sky and illuminates the whole family. The camera refers to the rainbow and the rural scenery after rain only when the family is pointing to them, viewing them and, more importantly, experiencing them. The once displaced natural beauty of Tibet presented to the outsiders is "returned" to its original place as an inherent part of it. The film breaks up with the sightseeing TV documentary such as Zangbei renjia (A Family in North Tibet, 1983) and transforms the Tibetan ordinary from a faraway face to a perspective, 
from being viewed to viewing; Tibet from a landmark of natural beauty to a perceived space ${ }^{22}$ of the locals. A subjective experience of Tibetan in cinema can be argued, although it is less complex.

\section{From "Standard Time" to "Local Time"}

Changing from a place to a space actualizes Tibet in the interaction between the scene and the locals. However, the transformation of cinematic space is always interwoven with cinematic time. In this part, I will examine the temporality of the new Tibetan documentaries and demonstrate a change from "standard time" to "local time." In China, only one standard time (Beijing Standard Time) is furnished by the government. Despite the three-hour time difference (in term of solar time) between the east and the west, Tibetan people are living in the Beijing Standard Time. A gap can be observed between the national standard time and local time. In the following analysis, I use the Beijing Standard Time and the Tibetan solar time as tropes for a homogenized time as progress promoted by the national narrative and a non-linear and heterogeneous time presented in the new Tibetan documentaries.

As mentioned earlier in the first section, socialist idealist documentaries on Tibet associated with a state discourse that privileged class struggle, liberation and modernization. In regards to temporality, the old documentary reveals a strong sense of time as progress, formulating a binary opposition between a backward, undeveloped and thus miserable past, and a modern, developed

22 "Perceived space" is a term from Henri Lefebvre's articulation of a perceived-conceived-lived triad of spatial practices, representation of space, and representational space. See Henri Lefebvre, The Production of Space, Blackwell: Oxford, 1991, pp. 38-40. 
and thus happy present or future. The fact that most titles of the official documentaries in the 1950s carry metaphors such as sunshine, bright, and spring when "celebrating" the liberation and modernization achievements in Tibet best illustrate this point.

In Duan Jinchuan and Ji Dan's films, time repeats itself rather than constantly moving forwards. Both of the films capture the quotidian life of Tibet, one in a domestic space and one in a public one. Several similar scenes repeat one another at different points of the film. In No.16 South Barkhor Street, for example, a similar scene of administrative meeting before the Tibetan New Year at the beginning of the film is repeated at the third shots before the Sakadawa Festival in April (Tibetan calendar); the scene of neighborhood committee handling with a family quarrel is repeated by another similar scene of them mediating a financial dispute between two neighbors; theft occurs three times throughout the whole film. In Ji Dan's work, Tibetan rural life repeats in daily household and nomadic works. Even the emotion of the protagonist - upset or happiness is recurring, although the filmmaker names the film as Gongbo's Happy Life. As Duan Jinchuan responds in an interview when asked about the gap between investigation (pre-work) and filming, “events repeat themselves constantly; something happened in the past will recur in another one's life. If you have enough time and patience to film, it absolutely will happen again. Despite the difference in degree, but they do have something similar." ${ }^{, 3}$ Although he didn't put it straightforwardly, the sense of non-linear time does influence him to a large extent in cinematic work.

${ }^{23}$ Interview with Duan Jinchuan. See Wang Weici, Jilu yu tansuo, p. 134. 
The conception and representation of non-linear time in the two films dismantle a totalizing narrative of progress articulated in the earlier documentaries. They redirect us to the quotidian Tibetan life, or in other words, to the regularity of it. However, that doesn't repudiate the unpredictability of it. As Gosetti-Ferencei reminds us, "the quotidian is that background in contrast to which new discoveries emerge and we are surprised; and more pointedly, it is a necessary condition for surprise, the regularity in contrast to which something new and unexpected occurs."24

No.16 South Barkhor Street favors a fly-on-the wall style and "pure observation",25 and sets its camera as an anonymous eye among the others on the spot. That is to say, it experiences time as it flows in nature instead of manipulate it. Duan Jinchuan is quite conscious of his use of real time in editing the film. In the second half of No.16 South Barkhor Street, Duan films a clock on the desk for 5 seconds, with its second hand moving for 5 seconds. This shot is remarkably revealing for its synchronization of real time and cinematic time. The real time forces the audience to enter the space, experience the time as the subjects do, and open to whatever is happening at the next moment as the subjects are. Of course, it shouldn't be forgotten that a sense of real time also coexists with the frequent use of long take in the new documentary in favor of on-the-spot realism. ${ }^{26}$ As Luke Robinson remarks in his monograph on independent Chinese documentary, xianchang (or on-the-spot) gives us a sense of time as "in-the-now,"

\footnotetext{
24 Jennifer Anna Gosetti-Ferencei, The Ecstatic Quotidian: Phenomenological Sightings in Modern Art and Literature, University Park: Pennsylvania State University Press, 2010, p. 1. My emphasis.

${ }^{25}$ See Chris Berry," Independently Chinese."

${ }^{26}$ Chris Berry, The New Chinese Documentary Film Movement, p. 7.
} 
which "suggests a transition from a modernist sense of time as progress, to one in which time is contingent, unpredictable, and bounded by the present." 27

The real time opens itself to spontaneity and therefore carves out room for some meaningful phenomena that are hard to catch in one narrative framework. One example can be taken from Gongbu's Happy Life. Two spontaneous scenes draw one's attention to the dynamic between the state discourse and local culture in a domestic space: while the camera is aiming at Gongbo and his friend drinking and dancing at home, one of Gongbo's girls interrupts, performs a salute and begins marching up and down with her inaccurate Mandarin instruction. Later on, she interrupts again and sings a patriotic song - "We all have one family, called China," with her right hand up over the head; ${ }^{28}$ at another night before the dinner, the girl describes the scene when they took an oath (in Tibetan) before putting on the red scarves and being admitted as a young pioneer. These fragmented moments give the audience a glance at the penetration of national culture through school students to a domestic space at a local level.

\section{Beyond "Minority Discourse": Temporal-spatiality and Power Dynamic}

Till now, I have demonstrated a change of space and time from a homogenized one in the official documentary to an open one in the new Tibetan documentary. By addressing the change from place to space, and from "standard time" to "local time," I read the significance of new Tibetan documentary in term of its capability to take on a local Tibetan perspective and to open

\footnotetext{
27 Luke Robison, Independent Chinese Documentary: From Studio to Street, New York: Palgrave Macmillan, 2012 , p. 8.

28 This is a patriotic song by Gao Feng, Da Zhongguo (Great China), 1995.
} 
up possibility for polyphonic discourse. However, considering that the ethnic difference between the Han filmmaker and minority subject matters, a question of cultural power relation between the majority and the ethnic minorities in cinematic representation deserves more scrutiny. Therefore, in the last section, I will review some previous studies on the power dynamic between the Han and non-Han in minority film. By having a conversation with these studies on not only Tibetan documentary but also other cinematic forms including narrative films about the ethnic minorities, I hope to answer the question that whether the cultural power relation between the majority and the minority has changed.

How to position the diverse ethnic groups and present them has long been a top concern for the People's Republic of China, a nation with considerable ethnic diversity. In the 1950s, when the PRC government was built and begun to run the new nation-state, legitimacy to govern the ethnically different regions such as Mongolia, Xinjiang and Tibet was a huge challenge. Cinematic works on the minorities in this period served exclusively to legitimize the state and thus closely cooperated with state discourse. As mentioned earlier, they all fall into three types: class struggle and liberation, modernization, and celebration in a national event. These three themes sometimes present respectively and sometimes overlap and intertwine. Class struggle as one of the Communist Party's strategies to minimize inter-ethnic tensions and to create basis for a homogeneous culture ${ }^{29}$ was best articulated in not only documentaries but also narrative film. As Yingjin Zhang observes in his discussion on Nongnü (Serfs, 1963), a narrative film about

\footnotetext{
${ }^{29}$ See June Teufel Dreyer, China's Forty Millions: Minority Nationalities and National Integration in the People's Republic of China, Cambridge: Harvard University Press, 1976.
} 
class exploitation from the clansman and oppression from local religion leaders, minority people never occupy the subject position and exert agency in these works. Instead, they are "directed to pay homage to the nation-state."30

In the 1970s and early 1980s, artistic films such as Caoyuan ernü (Son and Daughter of the Grassland, 1975, by Fu Jie) and Xingfu zhi ge (Song of Happiness, 1981, by Guang Chunlan) diversified the film market. In Paul Clark's critique, these movies romanticize the ethnic minorities with exotic imagination, which he considers as an intrinsic desire of Chinese cinema searching for the exotic and strange, and which allows the audiences to "travel to 'foreign' lands without crossing the nation's borders" $" 31$ in a time when China was closed to the outside world. Dru C. Gladney goes further to read the exoticism of ethnic-minorities representation (in films and other cultural forms) as "oriental orientalism." ${ }^{32}$ He interprets the primitivitism of minorities as a testament to the modernity of Han in the dominant imagination. ${ }^{33}$

This representational mode was modified in mid-80s, when several narrative films, such as Daoma zei (Horse Thief, 1985, by Tian Zhuangzhuang) and Qingchun ji (Sacrifice of Youth, 1985, by Zhang Nuanxin), set themselves in an ethnic minority setting. Paul Clark highly praises these films for their non-exoticism, naturalism and authenticity in representing ethnic minority and their life. ${ }^{34}$ However, Gladney and Zhang, one after another, point out an unquestioned power structure between the majority and the minorities in these works - they challenge the state

\footnotetext{
30 Yingjin Zhang, Screening China, p. 116.

31 Paul Clark, "Ethnic Minorities in Chinese Films: Cinema and the Exotic," East-West Film Journal 1.2 (1987), pp. 15-31.

32 See Dru C. Gladney, Dislocating China: Muslims, Minorities, and Other Subaltern Subjects, Chicago: University of Chicago Press, 2004, chapter 4, "Making, Marking, and Marketing Identity."

33 Ibid., p. 63.

${ }^{34}$ Paul Clark, pp. 27-28.
} 
discourse (national narrative in Gladney's) that privilege nation-building and modernization to individuality and subjectivity, while reassert the modern/primitive assumption between Han and non-Han. ${ }^{35}$ Both Gladney and Zhang consent that ethnic minorities (Tibetans in Tian Zhuangzhuang's case and Dai girls in Zhang Nuanxin's case) are still the “Other” as a result of their viewing experience of defamiliarization and alienation to the audience. Zhang goes further and categorizes these two films as merely part of a Han "minority discourse" against the overwhelming state discourse in the 1980s, which doesn't necessarily change the power relationship between the Han and the minorities.

However, a minority discourse in one time could become another dominant discourse in another, and becomes the target of resistance for a new generation. Independent documentary filmmaking on ethnic minorities, Tibetans in this case, since the 90s has gone beyond the “minority discourse” defined by Zhang. Taking Duan Jinchuan and Ji Dan's films as examples, their cinematic representations of the minority on the one hand dismantle the homogeneity of national imagination on Tibet as a state discourse, as I have shown above, and on the other hand challenge the modern/primitive assumption between Han and non-Han, as I will show below.

The modern/primitive assumption is problematic since it actually creates two separate temporal-spaces, positioning one behind another in a time line. However, Duan Jinchuan and Ji Dan put their Tibetan subjects and the Han majority in a parallel position. To begin with Duan Jinchuan, a non-interventionist observation actually leads to a viewing experience that "neither

\footnotetext{
35 See Dru C. Gladney, "Tian Zhuang, The "Fifth Generation \& 'Minority Film' in China: An Review Essay,” Public Culture 8.1 (1995): pp. 161-175; and Yingjin Zhang, From "Minority Film" to "Minority Discourse," in Screening China.
} 
romanticizes or mysticizes Tibetan life" ${ }^{36}$ From tedious meetings on local security to miscellaneous administrative matters (e.g. registration and accounting); from investigation of theft to mediation in family or neighborhood quarrels, all can find counterparts in contemporary mainstream society. In fact, Duan Jinchuan did have an idea of filming a similar documentary in a common police station in Beijing before he made No.16 South Barkhor Street. But a neighborhood committee became his final choice thanks to its accessibility. ${ }^{37}$ Similar to its counterparts in another Han-habited region, ordinary Tibetan people are in an ongoing engagement with the state and government. ${ }^{38}$ The film refuses to exoticize and abnormalize the ethnic minority. Instead, it presents Tibetans as real and living people, who share the normality with the majority. Therefore, the importance of No.16 South Barkhor Street lies on not only an emergence of a Tibetan public space, but also its effort to normalize Tibetan life.

If Duan Jinchuan's film shows a normalized Tibetan in a public space, Ji Dan's work achieves the same goal in a domestic space. If we are convinced by Gladney's comment on the "folklorization" of minority cultures ${ }^{39}$ and its problematic of marking out an "abnormal" other, Ji's work shows a subversion of "folklorization." Colorful clothes, exotic cuisine (e.g. buttered milk tea and barley liquor) and other religious decoration disappear from the screen. On the contrary, filmed in natural light, all are dimmed in the camera. What Ji Dan concern herself more

\footnotetext{
${ }^{36}$ Lü Xinyu, "Rethinking Chinese New Documentary Movement," in Chris Berry, The New Chinese Documentary Film Movement, p. 36.

37 See interviews with Duan Jinchuan in Chris Berry “Independently Chinese,” Wang Weici Jilu yu tansuo and Lü Xinyu Jilu Zhongguo.

38 By saying this, I am not denying the Tibetan particularity in the local-state dynamic. The films are full of intriguing moments regarding ethnic difference, such as the shift between standard Mandarin and local Tibetan dialect, and conflict between Han small business and Tibetan homeless.

39 Dru C. Gladney, Dislocating China, p. 99.
} 
with is their quotidian life, where she finds setbacks as well as joy of ordinary characters.

Although Lü points out a utopian impulse in her work, ${ }^{40}$ Gongbo's Happy Life indeed departs from utopian discourse in the other works. This film doesn't assume an untainted Tibetan village isolated from the outside world, especially the pollution and alienation of modernization. Instead, Gongbo and his family are experiencing modernization and undergoing great financial pressure Gongbo took out a loan for a tractor but found it difficult to pay it back, and his oldest son failed to live up his expectation and make big money in the city. It is not a suspended world in the past, to which modern people can go back, as suggested in a Mandarin rock-and-roll song, Back to Lhasa (Zheng Jun, 1994), and other mainstream TV documentary for sightseeing. Confronting similar modernization problem, it is the company of his family and friends that keep Gongbo positive and happy. Therefore, what Ji Dan presents is not a beautified space in the past where she and her audience can seek spiritual comfort, but an ordinary middle-age man and his ability to be happy in an unpleasant situation, from which its audience can gain inspiration for living.

Conclusion: New Tibetan Documentary, Now and Then

Documentary's claim of objectivity and its factualist assumption has long been challenged in cinematic study. Dai Vaughan has pointed out the representational ambiguities of documentary, "Documentarists ... like to believe that documentary is the 'natural' form of cinema. But fiction film, like painting and literature, rests no special claims upon the provenance of its linguistic

${ }^{40}$ Lü Xinyu, "Rethinking Chinese New Documentary Movement," p. 36. 
elements. It must surely be clear that it is documentary which is paradoxical, even aberrant form." ${ }^{, 41}$ Rey Chow in her innovative study on Chinese ethnography films reads Dai's emphasis on the viewer's role in constructing meaning as "a deconstruction of ethnography's fundamental claim to being simply a "record' rather than a language."42 That is to say, similar to narrative films, documentary is a language or a discourse, which is strong in construction and subjectivity. What the documentary filmmakers film, how they film and for what purpose are all problems to be scrutinized.

It is with this anti-factualism premise of documentary that I read new Tibetan documentary in the 1990s in a larger picture of the new documentary movement and that of the independent cinema in its national scope. They share the same goal of pursuing individuality and subjectivity in cinematic expression against an overriding state discourse in socialist China. New Tibetan documentaries have demonstrated a tendency to break up with the grand narrative of national solidarity and modernization, and to open up new Tibetan temporal-spatial issues. A more intimate relation between the cinematic temporal -space and the Tibetan locals further carves out room for the representational complexity of contemporary Tibetan life. These films have also shown the capability to go beyond a modern/primitive assumption and thus beyond the temporal asymmetry between the ethnic majority and the minority. Putting the Tibetan subjects in a position of being contemporary with the Han majority rather than in a position of being left

\footnotetext{
41 Dai Vaughan, "The Aesthetics of Ambiguity” in Peter Ian Crawford, and David Turton. Film as Ethnography, Manchester: Manchester University Press, 1992, p 102.

42 Rey Chow, Primitive Passions: Visuality, Sexuality, Ethnography, and Contemporary Chinese Cinema. New York: Columbia University Press, 1995, p. 240, footnotes to Dai Vaughan.
} 
behind in the past, the new Tibetan documentary succeeds in presenting a ? Tibet, a Tibet that is not restricted to the past but rooted in the present, moving towards a future.

Although Duan Jinchuan and Ji Dan's films show their significance in terms of a creative subversion of homogenized representation and for the ground they have broken for a less controlled and more nuanced cinematic world of Tibet, some pivotal issues regarding power dynamics between the majority and the minority are still unaddressed: To what extent can a Han filmmaker represent Tibetan and ethnic minorities? Can a film achieve subjectivity of both the director and the subjects? How will the power dynamic change if a Tibetan filmmaker is involved? As Rey Chow has observed in Primitive Passions, the deadlock of the anthropological situation between the observer and the observed, and between First World and Third World culture overshadows the cinematic communication. Inherent inequality and the asymmetry of privileges continue to mark the cultural translation between the two. ${ }^{43}$ This binary structure between the western observer and the East observed finds its counterpart between the ethnic majority and the minority within China. Despite great endeavors to approach the Tibetan real life, the meanings of these Han-made Tibetan documentaries are inevitably constructed by Han subjectivity and concerns - for Duan Jinchuan, it is the dynamic of public sphere, and for Ji Dan, it is the pursuit of happiness in quotidian life.

New Tibetan documentary in the 1990s and early 2000s is an integral part of China's new documentary movement and independent cinema. New voices and epistemology in this period

\footnotetext{
43 Ibid., p. 177.
} 
arise exclusively from the Chinese-language cinema. However, an emerging field of Tibetan cinema by directors with Tibetan background is expected to complicate the picture in the recent years. Early in 2010, a Tibetan herdsman Lance was given a camera (by an anthropologist) and filmed the nomadic daily life in his own village, which is presented in a documentary named Yak Dung. In recent years, a Tibetan director Pema Tseden also has risen as a star in Tibetan narrative filmmaking. His latest work Tharlo (2015) was invited to the Venice International Film Festival and the Busan International Film Festival, and won a Golden Horse Award in Taiwan. Later on, Tharlo's leading actor Shide Nyima filmed his first documentary work Tsezung Lhamo (2016), which had its first screening at the Tibetan Studies Center in University of Virgina. How Tibetan cinema by Tibetan directors constructs new meanings of Tibetan life and culture, what Tibetan subjectivity it presents, and how does it response to or negotiate with the Han-made as well as westerner-made works deserve further research.

As Rey Chow state eloquently in her emphasis of the "to-be-looked-at-ness" in Chinese-language ethnography films: "I believe that a new ethnography is possible only when we turn our attention to the subjective origins of ethnography as it is practiced by those who were previously ethnographized and who have ... taken up the active task of ethnographizing their own culture,"44 a newer Tibetan documentary or Tibetan cinema will come from Tibetan filmmakers, who take up cameras to represent themselves.

\footnotetext{
44 Ibid., p. 180. "To-be-looked-at-ness" is a concept that Chow borrows from Laura Mulvey, see Laura Mulvey, Visual Pleasure and Narrative Cinema, London: Palgrave Macmillan, 1989.
} 


\section{Works Cited}

Berry, Chris, Lü Xinyu, and Lisa Rofel, eds. The New Chinese Documentary Film Movement: for the Public Record. Hong Kong: Hong Kong University Press, 2010.

Certeau, Michel de. The Practice of Everyday Life, translated by Steven Rendall. Berkeley: University of California Press, 1988.

Chow, Rey. Primitive Passions: Visuality, Sexuality, Ethnography, and Contemporary Chinese Cinema. New York: Columbia University Press, 1995.

Clark, Paul. "Ethnic Minorities in Chinese Films: Cinema and the Exotic," East-West Film Journal 1.2 (1987), pp. 15-31.

Chu, Yingchi. Chinese Documentaries: From Dogma to Polyphony. London: Routledge, 2007.

Dreyer, June Teufel. China's Forty Millions: Minority Nationalities and National Integration in the People's Republic of China, Cambridge: Harvard University Press, 1976.

Gladney, Dru C.. Dislocating China: Muslims, Minorities, and Other Subaltern Subjects, Chicago: University of Chicago Press, 2004.

---. "Tian Zhuang, The "Fifth Generation \& 'Minority Film' in China: An Review Essay," Public Culture 8.1 (1995): pp. 161-175.

Gosetti-Ferencei, Jennifer Anna. The Ecstatic Quotidian: Phenomenological Sightings in Modern Art and Literature, University Park: Pennsylvania State University Press, 2010.

Halberstadt, Ira. "An Interview with Frederick Wiseman." In Nonfiction Film: Theory and Criticism, ed. Richard Barsam, New York: E.P. Dutton \& Co., 1976.

Lefebvre, Henri. The Production of Space, Blackwell: Oxford, 1991.

Lü Xinyu. Jilu Zhongguo: Dangdai Zhongguo xinjilu yundong (Recording China: Contemporary Chinese New Documentary Movement). Beijing: Sanlian shudian, 2003. 
---. "Xinzhongguo shaoshu minzu yingxiang shuxie: Lishi yu zhengzhi” (New Chinese Ethnic Minorities Cinema and Writing: History and Politics), Shanghai: Journal of Shanghai University (Social Science), Vol. 32, No. 5.

Pickowicz, Paul G, and Yingjin Zhang, eds. From Underground to Independent: Alternative Film Culture in Contemporary China. Lanham: Rowman \& Littlefield Publishing Group, 2006.

Qian, Ying. "Power in the Frame: China's Independent Documentary Movement." Chinese Media (2013).

Robison, Luke, Independent Chinese Documentary: From Studio to Street, New York: Palgrave Macmillan, 2012.

Vaughan, Dai. "The Aesthetics of Ambiguity" in Peter Ian Crawford, and David Turton. Film as Ethnography, Manchester: Manchester University Press, 1992.

Wang Weici. Jilu yи tansuo: Yu dalu jilupian gongzuozhe de shiji duihua (Record and Explore: A Century Dialogue with the Documentary Filmmakers in Mainland), Taibei: Yuanliu chuban gongsi, 2000.

Zhang, Yingjin. Screening China: Critical Intervention, Cinematic Reconfigurations, and the Transnational Imaginary in Contemporary Chinese Cinema. Ann Arbor: The University of Michigan, 2002.

---. Cinema, Space, and Polylocality in a Globalizing China. Honolulu: University of Hawaii Press, 2010. 